(i-COME'20)

INTERNATIONAL CONFERENCE ON COMMUNICATION AND MEDIA 2020

\title{
THE IMPACT OF CONFUCIANISM ON INTERPERSONAL COMMUNICATION AMONG YOUNGER GENERATIONS
}

\author{
Joyce Cheah Lynn-Sze (a)*, Pua Kit Yin (b) \\ *Corresponding author
}

(a) Universiti Utara Malaysia, 06010 Sintok, Kedah, Malaysia, joycecheah@uum.edu.my

(b) Universiti Utara Malaysia, 06010 Sintok, Kedah, Malaysia, jyin0006@gmail.com

\begin{abstract}
Many recent studies provided much insight into Confucianism values and practices in Asia. However, not many studies have been conducted to compare the similarities and differences in Confucian values between countries. Thus, the objective of this study is to explore the understanding of Confucianism on interpersonal communication from the perceptions of the Chinese students from Malaysia and China. The specific aims of this study are to identify the Confucian values practiced in the Chinese society and the impact on interpersonal communication from the perceptions from both countries. In-depth interview with 12 Chinese students, six students from China and six students from Malaysia from one the of public universities in Malaysia were conducted. Based on the findings, there are three perceptions about Confucianism which are moral values, cultural teachings and "not a religion". Besides, there are three impacts of Confucian values which influenced the Chinese students from China and Malaysia, such as effective communication, sustaining a harmony relationship and increase self-credibility. The study presented will clarify the similarities and differences between the two countries with regard to Confucianism and thus provide many hints for understanding the two countries.
\end{abstract}

2357-1330 @ 2021 Published by European Publisher.

Keywords: Confucianism, impact of Confucianism, interpersonal communication, perception of Chinese students 


\section{Introduction}

Confucian values are widespread throughout East Asia, China, Taiwan, Hong Kong, Singapore, South Korea, and Japan (Huang \& Chang, 2017). Scholars have long claimed that Confucian values affect social norms, influence individual decision making, and possibly to interpersonal communication (Chuang \& Wang, 2018). Confucianism had a major influence on the Chinese life for two thousand years, so an understanding of the influence of Confucianism is essential for successful teaching in East Asia. C

Confucius or Kong Fuzi was born around 551 BC in the Zhou Dynasty. Confucius is the most influential philosopher in the Chinese history that provides a guideline for proper behaviour (Yan \& Sorenson, 2006). While Kong Fuzi acknowledged as the innovator of Confucianism, he had a huge influence in China that followed by over 3,000 students and 72 disciples who transmitted his teachings in Analects of Confucius.

In China, Confucianism uses discipline to guide human in their learning. According to Choi and Niemine (2013), Confucianism showcased the importance of education, which to this day remain obvious in East Asian societies especially China with their focus on education. Besides, Confucianism has been emphasized in the aspects of life, including arts, history, social life and government. The findings found out that Chinese students placed a higher concern on certain values, such as respect to older people, hardworking and filial piety. According to Swain (2017), China was emphasised the study of Confucianism in the education fields to ensure the Confucian values such as humanness (ren), propriety (li), righteousness (yi) adapted by their students.

In the context of Malaysia, Confucian values was passed down through the Chinese education since the 19th century. The Malaysian Chinese immigrants have continued to practice and promote the Chinese traditional culture seriously after they immigrated to Malaysia. Since the early Chinese education system until today, moral values has always been the focus for the Malaysian Chinese (Liew \& Yam, 2018). However, Confucianism was categorised in the minority philosophy that adapted by Malaysians because of the multi-races and influences of other cultures in Malaysia (Liew \& Yam, 2018).

Although there have been changes in applications in the world today, Confucianism is still very much apparent in Chinese society (Marginson, 2011). Even some contemporary principles and practices have been introduced in the current Chinese culture, some traditional values still persisted (Marginson, 2011). Asian cultures are still based on moral values and displaying collectivism in their culture.

Therefore, this article attempts to understand how Confucian values influences the younger generations between the Chinese Malaysians and Chinese in Mainland China on interpersonal communication, as influenced by value systems in Malaysia and Confucius' philosophical foundations in China. This research will increase the understanding of the comparison between local and international Chinese youth besides provide more information about Confucianism values that insists in Chinese society in the last 2,500 years ago. 


\subsection{Confucian values}

According to Chan and Jiang (2017), there are five constants of Confucianism: Ren, Yi, Li, Zhi and Xin. According to the researcher, ren 仁emphasizes the obligation of humaneness and love toward others, while Yi义 or righteousness promote that people should distinguish appropriate (good) behaviour from impertinent behaviour which should not seek or get private benefits at the expenses of others (Fang \& Faureb, 2011). On the other hand, Li 礼 advocates on proper social behaviour or norms that provide as guidelines for ethical behaviour (Rosemont \& Ames, 2016). Zhi 智 focuses on wisdom or having the knowledge to say what is true. In term of xin 信, people should keep his/her promise and should not reveal people privacy that will affect the trustfulness of a person. Furthermore, Confucius also added some good values such as zhong 忠 (loyalty) in social interaction, xiao孝 (filial) in family, zhong yong 中庸 (the mean in common practice) in individual cultivation and cheng诚 (sincerity) which are solved the social problems in term of moral issue.

Generally, we acknowledged that Chinese are more value-oriented and concerned with social stability, humaneness and righteousness (Yeo et al., 2017). Similarly, Pohl (2002) conducted a comparative study of value preferences indicated that Chinese students emphasized on collectivism compared to Australian students. While Hong and Howes (2014) study stated that Chinese were found to have a higher concern of cooperation, togetherness and maintaining good relationship. Chinese children were also mentioned to have fewer interpersonal conflicts and confrontations (Domino \& Hannah, 1987).

\subsection{Malaysian Chinese culture}

In Malaysia, ethnic Chinese people are born and raised in Malaysia. They are one of the minority ethnic groups in Malaysia, which consists of three main ethnic groups, Bumiputra (70\%), Chinese (23\%), and Indians (7\%) (Department of Statistics Malaysia, 2015). Although most of the Malaysian Chinese are generally from multiple generations in China, it is common among Malaysian Chinese to maintain their culture, religious practices and identification with their heritage.

According to Chuah et al. (2016), the traditional Chinese cultures such as Confucianism among Malaysian Chinese obtained from the immigrant experience and exposure to Western culture in colonised settlement nations. Therefore, the existing Confucian values were not completely retained or adapted because Chinese heritages under different historical transition have developed different practice of the Confucian Analects.

According to Cheah and Ahmad (2017), Malaysian Chinese still emphasising on Confucian values in the context of leadership communication. Based on the study, Confucianism values will create a good leader and maintain the harmony relationship between leader and follower. There are three values that mentioned by leaders which are wisdom, trust and filial piety. Besides, Malaysian Chinese also agree with the benefits and positive influences that bring by these values and enhance the effectiveness in leadership. Thus, leader should understand and emphasise the Confucian values that effective in improving the leadership practice in general. 


\subsection{Confucianism in China}

$\mathrm{Wu}(2015)$ stated that education in the modern era of China, Confucius teaching is still adopted as a symbol representing Chinese culture. Scholars affirmed Confucianism is to maintain and develop Confucian thoughts among the followers (Tang, 2015). Researchers still believed that moral values in human relationships are still valued and practiced because they are important into the development of the younger generation. Furthermore, Confucianism that emphasised a harmonious and personal moral cultivation will maintain harmony in Chinese society (Tang, 2015).

Although China has experienced rapid economic growth and social changes over the years, many Confucian norms and practices still exist and have continued until today (Ebrey, 2014). While Zhou et al. (2019) showed that juniors still have to show respect to their seniors, while seniors are expected to give valuable advice and offer assistance to juniors.

\section{Problem Statement}

Previously, scholars have been conducting research that focused on the comparison of values in China and Western countries (Huang \& Chang, 2017). There are limited research on comparing the traditional values of people from the same cultural tradition but being brought up in different environment. Thus, it is very interesting to explore into the values held by younger generations from Malaysia and China. Tamai and Lee (2002) stated that Confucian values have gone through different processes of history in each country. There must be some differences in perceptions and understandings of Confucian value between Chinese youth in Malaysia and China. It is necessary to bring out a research on the perception and the impact of Confucian values that inhibits in Malaysian Chinese.

In addition, there are insufficient study done on younger generations in Malaysia about the Confucianism philosophy. Chinese values in Malaysia that live in a multi-national cultures where most of the population is Malay might influence by the other cultures. In this context, Truong et al. (2016) pointed out that a culture cannot understand specific practices, behaviours, and beliefs unless considering the culture of which they take part. According to Tan (1983), Malaysian Chinese do not have a definite term for their traditional religion and diffused into various aspects of Chinese culture. He also stated that most of the Malaysian Chinese misconception's Confucianism as a religion. The political factor determines ideology of the country and further influences education policy in Malaysia (Storz, 1999). Besides, the central element of a culture or civilization are moral values and communication. For example, some political leaders and scholars in Eastern countries will put "Asian values" to distinguish from Western "universal values". Therefore, it is necessary to bring out a research on the perception and characteristics of Confucian value that inhibits in Malaysian Chinese.

Besides, there are not many studies on the impact of Confucian values in fact the moral values still have a strong influence and concurrently exist with the new social values (Truong et al., 2016). Confucian values are still highly valued in society among East Asian countries that bring benefits to student's everyday life. According to Kang et al. (2017), over 20\% of the world's population infuses to Confucian culture that provides guidelines for the correct behaviour of an individuals in community. It cannot be denied that not all East Asians would follow the Confucianism values in interaction or communication in 
the community, but they are likely to influenced by the Confucian cultures in which they live. The consideration of cultural issues that influence by Confucian values become increasingly important in Chinese society (Huang \& Chang, 2017). Therefore, a study on how Confucian values impacted the Malaysians and mainland Chinese will be able to increase the understanding of Confucian values in their interpersonal communication.

\section{Research Questions}

- What are the perceptions of the Chinese students in Malaysia and mainland China on Confucianism?

- How does Confucian values impacted the Chinese students in Malaysia and mainland China on interpersonal communication

\section{Purpose of the Study}

The purpose of this study is to understand how Confucian values influences the younger generations in Malaysia and Mainland China on interpersonal communication.

- To understand the perceptions of the Chinese students in Malaysia and mainland China on Confucianism.

- To determine how does Confucian values impacted local and international Chinese students' everyday life

\section{Research Methods}

Researchers used in-depth interview in collecting data to gather a better understanding of the Confucian values among local and international Chinese students. This study involved 6 local and 6 international Chinese undergraduate students in Universiti Utara Malaysia. All data collected were transcribed by the researchers. Data transcribed were imported and analysed using Nvivo 8 .

\section{Findings}

\subsection{Perceptions of Confucianism}

\section{- Moral values}

Moral values are principles that one follows to distinguish the right and the wrong that related to the fundamental human emotions and experiences that motivate human in various ways (Harbour, 2012). Based on the interviews, both Malaysia and China students think that Confucianism inhibit good moral values that are worth to follow and learn. The informants stated that Confucianism as moral values that help and guide people in developing a better personality and guidelines for avoiding bad habits and values.

Informant 1 said that she learned about Confucian values for instance filial piety and humanness through her parents and teachers by story-telling. She thinks that Confucianism provided the moral values 
that should be followed and adapted to create a harmony relationship between human to build a better personality and society.

"These values and knowledge were taught by teacher in primary school. Teachers in primary school encouraged students to adapt Confucian values by giving small gifts as a motivation to students that well-behave during school”. (Informant 2)

\section{- Cultural teaching}

Cultural teaching is a teaching that shapes the thinking process of groups and individuals (Garmeau, 2014). Based on the interviews, informants think that Confucianism is a cultural heritage that should be pass down to next generation. Informant 5 from Malaysia said that Confucianism is a teaching that were passed down from ancestors while Informant 6 from China stated that Confucianism is a teaching that originated from China.

Confucian values were implied in human everyday life that caused us to perceived that Confucianism is a cultural teaching that contributed to a lot of good values, behaviours that should be follow by everyone. (Informant 3)

\section{- Not a religion}

On the other hand, Informant 8 and 11 from China and Malaysia respectively have their opinion about Confucianism is not a religion. According to Ebrey (2014), most of the people emphasised on the theoretical forms of religion that important in practical expression and form of worship. Thus, informants think that Confucianism is not a religion that need to imply in practical procedure and worship.

Confucianism is not a religion because it does not have the requirement for applying the values of Confucianism in our daily life. Although there are Confucian temples worshipping, it does not make compulsory to all. Confucianism is just an ethical or moral teaching that can be adapted by everyone. (Informant 8)

\subsection{Confucian values and its impact}

Based on the interview, Confucianism provides many knowledge and wisdom that are beneficial for the society to create a morality community. Confucian values that enable a people to enhance the morality and build a better personality had played a significant role in student's daily life. There are several impact of Confucian values such as effective communication, sustain a harmony relationship and increase self-credibility

\section{- Effective communication}

Effective communication is defined as high completeness and effectiveness in conveying a message to receiver (Choi \& Niemine, 2013). The adaptation of Confucian values in daily life would also improve the effectiveness of communication among students' social circle. Confucian values such as propriety and filial attitude would help students transmit and convey the messages effectively to others. Informant 8 stated that truthfulness and righteousness that able to increase a person's self-credibility can 
also assist in the process of persuading or sharing information or ideas to others. This is because people would like to give more attention for people that is trustworthy and fair.

\section{- Sustaining a harmony relationship}

Sustain a harmony relationship refer to maintaining a peaceful relationship with others (Sim \& Chow, 2019). Furthermore, adapted Confucian values in daily life also able to sustain a harmony relationship with others. Confucianism that strongly emphasis about the harmonious and peaceful relationship lead people to appreciate the interaction and conversation with others. Besides, Informant 7 and 10 stated that a relationship can be improved by applying good values such as propriety, humanness, filial attitude. These values would improve the satisfaction in the conversation and interaction with others.

\section{- Increase self-credibility}

Increase self-credibility is enhanced the qualities of personalities in establishing a better self to others (Liu \& Kang, 2017). In the context of increase and enhance self-credibility, Informant 3 and 2 which come from Malaysia and China stated that Confucian values such as righteousness, truthfulness and self-discipline can increase a person's credibility. These values are important in create the performances, enhance the experiences besides improve the self-qualities. Moreover, increase selfcredibility would also contribute in the future works for students and become an additional advantage for students to get chances in future.

\section{Conclusion}

The findings showed that the perceptions of Confucian values are quite similar among Chinese students in Malaysia and China, and that some differences might be explained by social context. Beliefs and communication will be necessary if we inspire to achieve mutual understanding because perception of Confucian values vary across cultures. This research suggested that individuals seem to view interpersonal communication, such as communication between families and friends as central to good values. Overall, both Chinese students in Malaysia and China perceived Chinese values to be important. These comparisons intended to provide better insights on the perceptions of Confucianism on interpersonal communication that vary across Asian cultures. Based on the multi-cultural country in Malaysia compared to mainland China, it was clear that Malaysian citizen of the Chinese ethic background who were growing up in a friendly environment would put more emphasis on moral values when explaining about their everyday communication beliefs. In the age of interconnected world, it would be crucial to attain mutual understanding on how individuals make sense of their world.

\section{References}

Chan, T., \& Jiang, B. (2017). U.S. teachers' perception of Confucian teaching philosophies and methodologies. New Waves Educational Research \& Development, 20(2), 20-34.

Cheah, C. L. S., \& Mohd Khairie Ahmad (2017). Confucian value-based leadership communication: A study on Tun Dr. Mahathir Mohamad. Malaysian Journal of Communication, 33(3), 140-156.

Choi, S. H. J., \& Niemine, T. A. (2013). Factors influencing the higher education of international students from Confucian East Asia. Higher Education Research \& Development, 32(2), 161-173. 
Chuah, S., Hoffmann, R., Ramasamy, B., \& Jonathan, H. (2016). Is there a spirit of oversea Chinese capitalism? Small Business Economics, 47(4), 1095-1118.

Chuang, S. F., \& Wang, G. G. (2018). Confucian philosophy and influence on perceived values and behavioural orientations by Taiwan's millennials. Human Resource Development International, $21(4), 362-381$.

Department of Statistics Malaysia (2015). (updated May 2015). Population Distribution and Basic Demographic Characteristic Report. www.dosm.gov.my

Domino, G., \& Hannah, M. T. (1987). A comparative analysis of social values of Chinese and American children. Journal of Cross-cultural Psychology, 18(1), 58-77.

Ebrey, P. (2014). Confucianism and family rituals in imperial China: A social history of writing about rites. Princeton: Princeton University Press.

Fang, T., \& Faureb, G. O. (2011). Chinese communication characteristics: A Yin Yang perspective. International Journal of Intercultural Relations, 35, 320-333

Garmeau, A. (2014). Cultural competence: A constructivist definition. Journal of Transcultural Nursing, 26(1), 43-59.

Harbour, F. (2012). Basic moral values: A shared core. Ethics and International Affairs, 9, 155-170.

Hong, S. H., \& Howes, A. (2014). Influences of Confucianism on Chinese Parents' Experience with early childhood education. Open Journal of Social Sciences, 2(7), 39-49.

Huang, M. H., \& Chang, S. H. (2017). Similarities and Differences in East Asian Confucian Culture: A Comparative Analysis. OMNES : The Journal of Multicultural Society, 7(2), 1-40.

Kang, J. H., Matusik, J. G., \& Barclay, L. I. (2017). Affective and Normative Motives to Work Overtime in Asian Organizations: Four Cultural Orientations from Confucian Ethics. Journal of Business Ethics, 140, 115-130.

Liew, F. Y., \& Yam, K. K. (2018). The meanings of Heaven and human nature ideology in Pre-Qin Confucianism for Moral Education in Malaysia. Journal of Chinese Literature and Culture, 6(2), $27-45$

Liu, H., \& Kang, X. (2017). Suggestions on the construction of credibility of charitable organisations in China from the perspective of social capital. Economic, Business and Management, 529-534.

Marginson, S. (2011). Higher education in East Asia and Singapore: rise of the Confucian Model. Higher Education, 61(5), 587-611.

Pohl, K. H. (2002). Chinese and Western Values: Reflections on a Cross-Cultural Dialogue on a Universal Ethics.

Rosemont, H., \& Ames, R. T. (2016). Confucian Role Ethics: A moral vision for the $21^{\text {st }}$ century?. Taipei, Taiwan: National Taiwan University Press.

Sim, J., \& Chow, L. (2019). Confucian thinking in Singapore's citizenship education. Journal of Moral Education, 48(4), 465-482.

Storz, M. L. (1999). Malay and Chinese values underlying the Malaysian business culture. International Journal of Intercultural Relations, 23(1), 117-131.

Swain, T. (2017). Confucianism in China: An Introduction. Bloomsbury Publishing.

Tamai, K., \& Lee, J. (2002). Confucianism as cultural constraint: A comparison of Confucian values of Japanese and Korean university students. International Education Journal, 3(5), 33-49.

Tan, C. B. (1983). Chinese religion in Malaysia: A general view. Asian Folklore Studies, 42(2), 217-252

Tang, Y. (2015). Confucianism, Buddhism, Daoism, Christianity and Chinese Culture. Beijing: Foreign Language Teaching and Research Press.

Truong, D. T., Hallinger, P., \& Sanga, K. (2016). Confucian Values and School Leadership in Vietnam: Exploring the influence of culture on principal decision making. Educational Management Administration \& Leadership, 45(1), 1-24.

Wu, S. (2015). Modernizing Confucianism in China: A repackaging of institutionalization to consolidate party leadership. Asian Perspective, 39(2), 301-324.

Yan, J., \& Sorenson, R. (2006). The Effects of Confucian values on Succession in Family Success. Family Business Review, 19(3), 235-250. 
Yeo, K. H., Wildman, J. L., \& Choi, S. B. (2017). The effects of Confucian values on interpersonal trust, justice and information sharing of Korean workers: A multilevel analysis. Journal of Pacific RIM Psychology, 11(11), 1-11.

Zhou, A., Lapointe, E., \& Zhou, S. (2019). Understanding mentoring relationships in China: Towards a Confucian model. Asia Pacific Journal of Management, 36(2), 415-444. 